$16^{\circ}$ USIHC - Congresso Internacional de Ergonomia e Usabilidade de CINAHPA

\title{
PONTENCIALIDADES DE INTERAÇÃO DO GOOGLE HOME
}

\section{INTERACTION POTENTIAL OF GOOGLE HOME}

\author{
Cinthia Larissa da Costa ${ }^{1}$, Bel. \\ Berenice Santos Gonçalves ${ }^{2}$, Dra. \\ (1) Designer \\ e-mail:cin.verter@gmail.com \\ (2) Universidade Federal de Santa Catarina \\ e-mail:berenice@cce.ufsc.br
}

Design de Interação, Internet das Coisas (IoT), Smart Home

\begin{abstract}
A partir da influente ideia de conectar dispositivos eletrônicos à internet, surgem inovações tecnológicas que permitem uma nova interação com o ambiente circundante, transformando lares em locais "inteligentes" e possibilitando que sejam uma extensão do próprio usuário no dia a dia. Desta forma, o objetivo do artigo é analisar quais as potencialidades de interação do dispositivo Google Home com base nos princípios cognitivos de Norman [2006] e apresentar uma breve contextualização sobre o tema internet das coisas (IoT). O smart speaker Google Home é um produto em desenvolvimento que consegue auxiliar na interação com o lar, seu foco é entreter o usuário e não controlar de forma segura uma residência. Com a análise, percebeu-se que será necessário incluir mais funções para completar o sistema atual, assim, o usuário poderá identificar mais valor no produto. Essa discussão é atual, e o presente artigo não pretende esgotar o tema.
\end{abstract}

\section{Interaction Design, Internet of Things (IoT), Smart Home}

From the influential idea of connecting electronic devices to the Internet, technological innovations emerge that allow a new interaction with the surrounding environment, transforming homes in smart places and allowing them to be an extension of the user himself in the day to day. In this way, the objective of the article is to analyze the interaction potential of the Google Home device based on the cognitive principles of Norman [2006] and to present a brief contextualization on the Internet theme of things (IoT). The smart speaker Google Home is a product in development that can help in the interaction with the home, its focus is to entertain the user and not to control a residence in a safe way. With the analysis, it has been realized that it will be necessary to include more functions to complete the current system, so that the user can identify more value in the product. This discussion is current, and the present article does not intend to exhaust the theme. 
$16^{\circ}$ Ergodesign - Congresso Internacional de Ergonomia e Usabilidade de Interfaces Humano Tecnológica: Produto, Informações Ambientes Construídos e Transporte

$16^{\circ}$ USIHC - Congresso Internacional de Ergonomia e Usabilidade de Interfaces Humano Computador

CINAHPA | 2017 - Congresso Internacional de Ambientes Hipermídia para Aprendizagem.

\section{Introdução}

\subsection{Contexto e problemática}

Uma casa conectada, que liga experiências por meio da "tecnologia inteligente", é um conceito encontrado desde os anos 60 [Fjord, 2016]. Nesta época, Jim Sutherland, nos Estados Unidos, projetou e construiu o ECHO IV, um sistema de informática desenvolvido para controlar os aspectos de sua casa que interagiam com esposa e filhos. Conecta-se este histórico com o paradigma de interação da computação ubíqua de Mark Weiser [1991 apud Preece, 2013, p.55-56] que afirmava que "os computadores desapareceriam no ambiente de uma tal forma que não mais os perceberíamos (...) e melhorariam o mundo de hoje de uma maneira 'invisível', em vez de criarem novos mundos artificiais". Assim, observa-se que nesse sentido os dispositivos de internet das coisas vêm contribuindo para a relação das pessoas e os ambientes. Como cita a consultoria de design e inovação Fjord [2016], já é perceptível que as conexões de internet facilitaram as tarefas domésticas. Agora, acredita-se que as expectativas são de serviços ubíquos com poder de conduzir estas mesmas atividades para qualquer lugar, tornando a casa portátil.

A empresa Google, por meio do seu site ${ }^{1}$, descreve que o dispositivo de internet das coisas Google Home é um alto-falante ou smart speaker ativado por voz e alimentado pelo assistente de pesquisa da empresa. Mediante um só produto, é possível centralizar a interação do usuário com o seu lar, utilizando aplicativos e dispositivos que são compatíveis com o sistema do Google Home.

\subsection{Pergunta e objetivos}

Tendo em vista o contexto apresentado no tópico anterior e evidenciando os princípios cognitivos de interação [Norman, 2006], neste estudo busca-se responder a seguinte pergunta: Quais as

\footnotetext{
${ }^{1}$ https://madeby.google.com/home/ acesso 15/02/2017
}

potencialidades de interação do produto Google Home?

Portanto, o objetivo geral deste artigo é compreender por meio de pesquisa e análise como o alto-falante Google Home, se estrutura em relação aos recursos interativos. E os objetivos específicos são:

- Contextualizar o tema "internet das coisas" (Internet of Things, IoT);

- Analisar os aspectos cognitivos de interação tangíveis e virtuais do produto da Google.

Para a análise das potencialidades de interação, são adotados os sete princípios cognitivos de Norman [2006], a saber: (i) usar ao mesmo tempo o "conhecimento no mundo" e o "conhecimento na cabeça"; (ii) simplificar a estrutura das tarefas; (iii) tornar as coisas visíveis: encurtar ou superar as lacunas de execução e avaliação; (iv) fazer corretamente os mapeamentos; (v) explorar o poder das coerções naturais e artificiais; (vi) projetar para o erro; (vii) quando tudo o mais falhar, padronizar.

Preece, Rogers e Sharp [2013], descrevem as diversas facetas de como os usuários são afetados pelas interfaces, e levantam paradigmas da interação que auxiliaram no entendimento e posicionamento do produto. Para Murray [2012], os ambientes digitais são procedimentais, participativos, espaciais e enciclopédicos. A autora criou um grid com estes quatro affordances que será utilizado para verificar as propriedades de interações do Google Home. Os referenciais citados, são utilizados nos procedimentos de análise.

\section{Fundamentação}

Subhas Chandra Mukhopadhyay [2014] reuniu no livro "Internet of Things" artigos de diversos autores sobre os desafios e oportunidades relacionados à tecnologia e conectividade.

Segundo Mukhopadhyay [2014] o termo internet das coisas é usado para descrever dispositivos incorporados (coisas) com ligação à internet,
Realização:

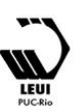




\section{$16^{\circ}$ \\ ERGODESIGN USIHC CINAHPA}

permitindo-lhes interagir uns com os outros, serviços e pessoas em escala global. Considera desde o meio ambiente, monitoramento, automação residencial até edifícios e redes inteligentes que podem ser interligados, permitindo que as informações sejam compartilhadas entre os sistemas.

Observa-se que o uso da internet está aumentando constantemente ao longo dos anos. De acordo com as estatísticas levantadas por Mukhopadhyay [2014], o número de usuários de internet no final de 2011 ultrapassou 2,2 milhões, baseado na distribuição geográfica, conforme ilustrado na figura 1 mostrada a seguir.

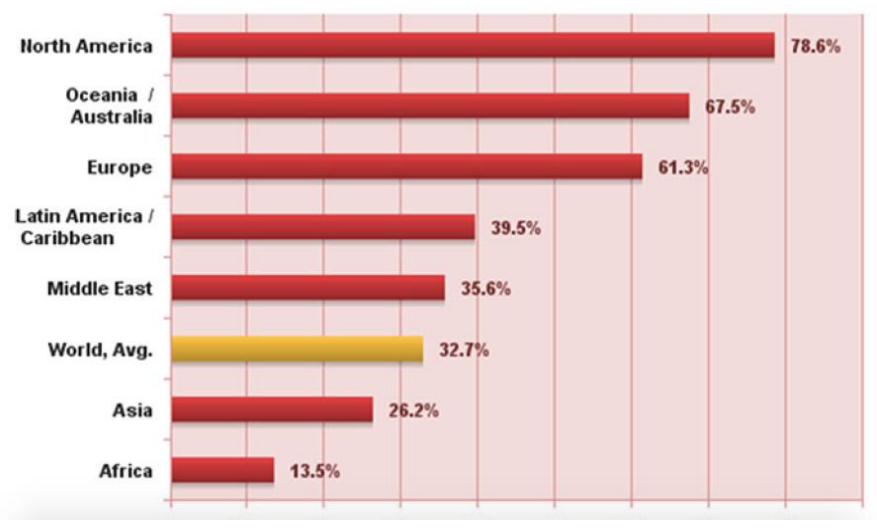

Figura 1: porcentagem de usuários de internet no mundo por regiões geográficas. Fonte: Mukhopadhyay [2014]

Com o aumento de usuários da internet, surgem mais tecnologias que interconectam facilidades e as pessoas passam a demandar mais produtos. Aos poucos, lares e pequenos estabelecimentos são automatizados, dado ao acesso e facilidade de uso dos dispositivos de internet das coisas, como a opção de instalação independente do tipo "faça você mesmo" e o uso de aplicativos amigáveis em smartphones.

No mercado global de 2016/2017 é possível encontrar esses produtos no varejo, principalmente nos Estados Unidos e Canadá, regiões onde grandes empresas já vêm apostando no desenvolvimento de IoTs. Em novembro de 2014 a Amazon lança o assistente virtual Echo, e dois anos depois a Google surge com um produto $16^{\circ}$ Ergodesign - Congresso Internacional de Ergonomia e Usabilidade de Interfaces Humano Tecnológica: Produto, Informações Ambientes Construídos e Transporte

$16^{\circ}$ USIHC - Congresso Internacional de Ergonomia e Usabilidade de Interfaces Humano Computador

CINAHPA | 2017 - Congresso Internacional de Ambientes Hipermídia para Aprendizagem. similar o smart speaker Google Home, pelo preço de US\$129.

Analisando a intenção dos produtos IoTs, observase que eles se adequam aos paradigmas de interação citados por Preece [2013] que são: (i) a computação ubíqua, no qual os produtos podem ser tecnologicamente inseridos no ambiente por meio de dispositivos inteligentes, (ii) a computação pervasiva que é a integração total de tecnologias, (iii) a computação vestível ou wearables, como tags e smartwatches, (iv) os "ambientes atentos" que atendem as necessidades dos usuários, (v) e o workday world que são os aspectos sociais do uso da tecnologia, como por exemplo o uso de aplicativos de dispositivos IoT que possuem uma rede confiável de pessoas (vizinhos e amigos) para colaborar na segurança de casas.

Os IoTs vem abrindo precedentes para os usuários quererem ou não automatizarem as camadas de controle do seu dia a dia [Norman 2006], como acionar o acendimento ou desligamento de luzes em horários específicos, abertura de portas por meio do smartphone ou por leitura digital, e comandos de voz para pesquisar informações sobre um filme, etc. Assim, as operações manuais acabam sendo realizadas pela inteligência do sistema e trazendo comodidade e foco maior para as atividades globais do usuário.

\subsection{Breve caracterização do objeto de análise}

No Brasil, o Google Home ainda não está disponível e a comunicação com o usuário funciona em inglês. Utiliza-se o comando de voz inicial "Ok Google" ou "Hey Google" para iniciar uma conversa e realizar atividades. Como a Google possui um rico banco de dados, o produto auxilia em buscas, sendo possível obter respostas em tempo real, incluindo informações mais recentes sobre clima, tráfego, finanças, esportes, empresas locais, entre outros. Também é mais uma forma de obter informações pessoais dos usuários, assim, o Google Home pode recuperar informações de voo, definir alarmes e temporizadores. Ele conecta dispositivos inteligentes, como os produtos de entretenimento e stream Chromecast, e os de 


\section{$16^{\circ}$ \\ ERGODESIGN USIHC CINAHPA}

$16^{\circ}$ Ergodesign - Congresso Internacional de Ergonomia e Usabilidade de Interfaces Humano Tecnológica: Produto, Informações Ambientes Construídos e Transporte

$16^{\circ}$ USIHC - Congresso Internacional de Ergonomia e Usabilidade de Interfaces Humano Computador

CINAHPA | 2017 - Congresso Internacional de Ambientes Hipermídia para Aprendizagem. automação residencial Nest e Philips Hue, para que seja possível ter maior automação de uma casa. Portanto, este smart speaker serve como ponte ou uma central amigável e personificada (devido ao comando de voz), interligando todos os aplicativos e dispositivos IoT compatíveis ao sistema Google que o usuário utiliza.

O produto físico, como já citado é um alto-falante que possui microfones de longo alcance e um processamento de linguagem natural. É possível ter o controle total do aparelho pelos dois alto-falantes e tocando a sua face superior, que se comunica com o usuário a partir da movimentação de quatro luzes (azul, verde, vermelho e amarelo - cores da empresa). O botão em sua face lateral permite que os microfones fiquem em modo de espera e mudos. Havendo mais de um Google Home, pode-se criar um sistema de som ambiente, agrupando-os e definindo uma música para todos os ambientes. $\mathrm{O}$ produto é branco na sua parte superior e sua base é fácil de remover e personalizável, podendo trocar por sete opções de cores, U\$20 cada uma. Além do produto físico, existe o aplicativo Google Home, onde é possível descobrir todos os conteúdos e recursos, e, por exemplo, ter o controle das configurações do provedor de música ou localização e compatibilidade com os dispositivos IoT. Sua interface é familiar aos usuários dos produtos Google.

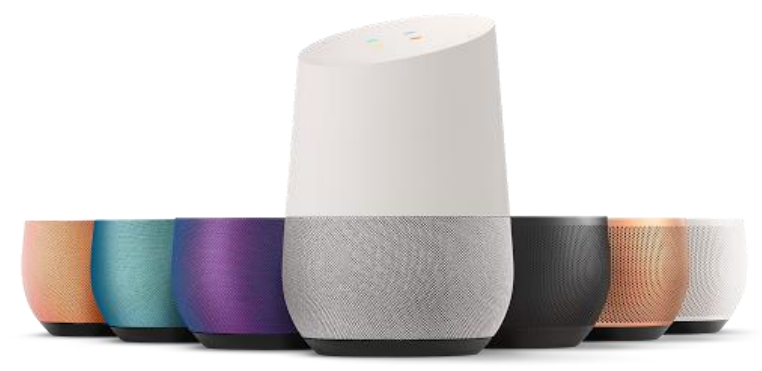

Figura 2: smart speaker Google Home produto. Fonte: https://madeby.google.com/home/ acesso em $15 \mathrm{de}$ fevereiro de 2017

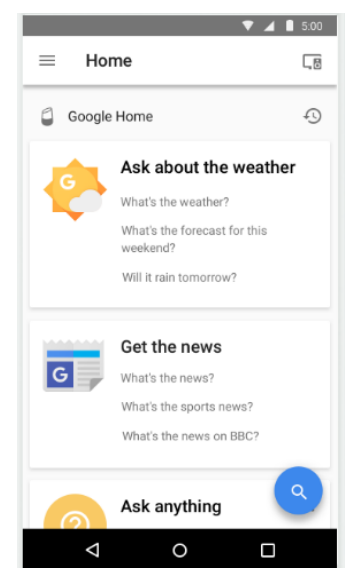

Figura 3: smart speaker Google Home interface. Fonte: https://madeby.google.com/home/ acesso em 15 de fevereiro de 2017

\section{$3 \quad$ Resultados e discussões}

A partir da análise realizada, observa-se que o Google Home colabora para a mimetização da automação residencial e também cria um vínculo de assistência com o usuário por meio de fala (comando de voz do usuário), audição (respostas que o produto fornece ao usuário), visual (luzes no topo do produto e uso do aplicativo) e toque (com o topo do produto sensível ao toque e botão na lateral que deixa o produto mudo ou em standby, e também o uso do aplicativo).

Para Murray [2012], algo feito em código de computador tem o potencial para a capacidade enciclopédica, para modelar espaços navegáveis, para descrever e executar comportamentos condicionais, e para apoiar a participação de interagentes. Essas propriedades fazem parte do grid das affordances criado pela autora com a função de verificar as qualidades de um objeto que permitem que ele seja posto em uso ou ação. Ao analisar, identifica-se as quatro affordances do grid no Google Home. 


\section{$16^{\circ}$ \\ ERGODESIGN USIHC CINAHPA}

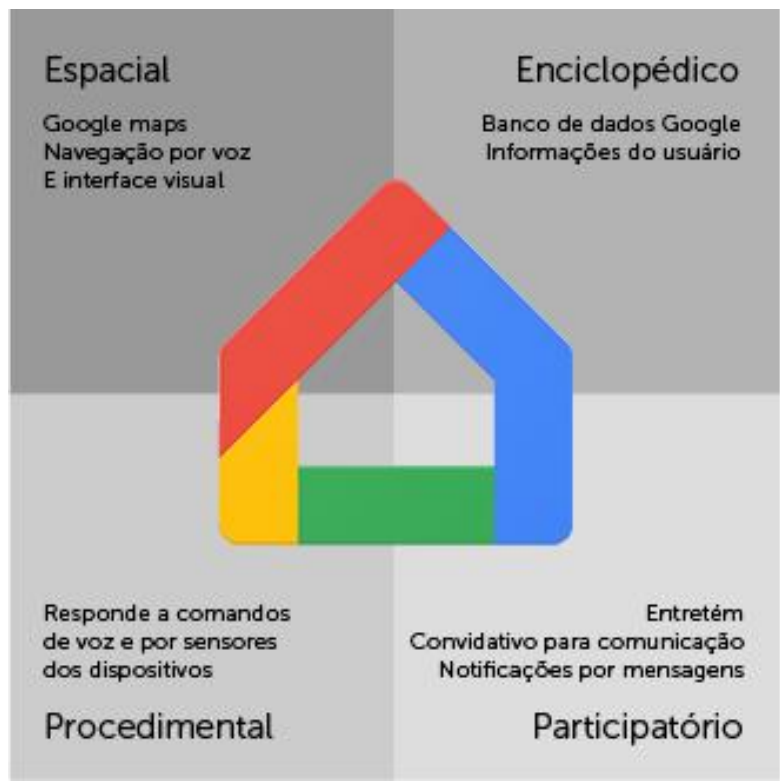

Figura 04: posicionamento do smart speaker Google Home no grid das affordances. Fonte: a autora [2017]

O quadrante "espacial" indica a navegação em um repertório de informações ou local virtual, no qual é possível por conversa e interface visual do smart speaker. No "enciclopédico" verifica-se a capacidade de informação do produto em vários formatos de mídias, devido o extenso banco de dados do Google e diferentes serviços prestados. Por ser executável por meio de solicitações do usuário e convidativo à ação humana, o produto também condiz com os quadrantes "procedimental" e "participatório".

Para a análise de uso, conectou-se um dispositivo Google Home em uma rede residencial Wi-Fi. O aplicativo foi baixado em um smartphone com o sistema Android. O tempo desta análise foi de aproximadamente $24 \mathrm{~h}$, onde foi possível extrair as primeiras interações com produto. Ao ligar o dispositivo, o aplicativo detecta que existe um novo Google Home, e o conecta na rede Wi-Fi solicitando o login com o ID Google. Por enquanto é possível vincular somente uma conta por vez. $\mathrm{E}$ segundo o suporte do Google $\mathrm{Home}^{2}$, qualquer um que estiver por perto pode conversar com o dispositivo e solicitar informações, até mesmo sobre o perfil da conta.

${ }^{2}$ https://support.google.com acesso 15/02/2017 $16^{\circ}$ Ergodesign - Congresso Internacional de Ergonomia e Usabilidade de Interfaces Humano Tecnológica: Produto, Informações Ambientes Construídos e Transporte

$16^{\circ}$ USIHC - Congresso Internacional de Ergonomia e Usabilidade de Interfaces Humano Computador

CINAHPA | 2017 - Congresso Internacional de Ambientes Hipermídia para Aprendizagem.

Alguns dos problemas observados em uso e por meio de relatos de usuários na internet informam que ocorrem alguns travamentos, bugs e problemas de identificação da rede no momento da instalação, o que acaba impedindo o uso imediato. Existe também a demora de feedbacks que muitas vezes podem depender da conexão da internet da residência, sendo uma questão não direta do produto. Seguindo os sete princípios cognitivos de Norman [2006], o primeiro deles diz que a imagem do sistema é a forma de comunicação do usuário com o designer, onde é possível ver seu funcionamento, maneira como reage e instruções que o acompanham. Neste caso, a "imagem" do sistema principal é o som, a interlocução de um sistema com o usuário, e é imprescindível que funcione e seja natural, para não ter a necessidade de recorrer ao aplicativo ou em último caso desligá-lo, quebrando a experiência do usuário.

O Google Home possui um alto-falante inteligente e pequeno, mas que atinge um som alto sem muita distorção. Apesar da robotização e de algumas interrupções, a voz do assistente soa próxima ao real e percebe-se que está consciente sobre o contexto da conversa. Sobre a estrutura das tarefas, segue pelo comando inicial "Ok Google" ou "Hey Google" se não fosse necessário toda vez que ativa o produto, poderia gerar uma interação mais intuitiva. Norman [2006] ressalta que é importante transmitir as informações sobre um objeto distante, tornando visível (ou audível) o que está acontecendo, e tornando possíveis as tarefas e atividades que de outro modo não seriam capazes. Esta é uma característica que pode ser cada vez mais relevante para o Google Home, pois sua ideia geral atende a simplificação de compreensão que reduz a carga de memória do usuário por meio da centralização do controle dos demais dispositivos IoT e aplicativos. Mas a funcionalidade do Google Assistente em geral ainda é um pouco limitada, ele não possibilita o acesso ao ecossistema completo do Google, como enviar e-mails, e também não vai muito além de informar quais tipos de eventos estão chegando no calendário. O sistema não permite adicionar novos eventos por meio de voz, mas sugere esta função em uma nova versão do produto.
Realização:

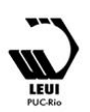




\section{$16^{\circ}$ \\ ERGODESIGN USIHC CINAHPA}

Norman [2006] destaca que nem sempre o sistema pode executar as atividades exatamente da maneira que gostaríamos, assim, sabe-se que a chance do Google Home não funcionar é grande, pois além de bugs e "funções por vir" ele depende de alguns recursos como a energia e a internet. Ocorrendo problemas com a operadora ou uma queda de energia prolongada, já impediria o controle de uma residência, posicionando o produto como um item de entretenimento em vez de controle da residência.

Mukhopadhyay [2014] lembra que a acessibilidade da internet, sem qualquer segurança pode ser uma grande questão, pois produtos IoT seriam mais uma forma para extrair informações privadas. Segundo a Fjord [2016] os usuários estão cada vez mais preocupados com a ideia dos algoritmos controlando o consumo das informações e com os produtos obtendo informações de privacidade. A tendência é que a população seja cada vez mais ativa no meio de leis e protestos sobre a segurança, privacidade e inteligência artificial.

\section{Conclusões}

Conclui-se que o smart speaker Google Home é um produto em desenvolvimento que possui potencialidades para auxiliar e simplificar a interação com uma residência que possua automação plug and play. Espera-se o aprimoramento das interações de comando de voz e interligação de mais ou relevantes serviços Google com o produto, para melhorar a experiência e trazer mais valor para os usuários. Este artigo não esgota o tema por aqui, planeja-se um cenário com mais dispositivos e uma experiência prolongada para conferir a interação residencial. A discussão é atual e possível de abordá-la em diferentes níveis, onde o objetivo será ampliar e aprofundar o tema em estudos futuros. $16^{\circ}$ Ergodesign - Congresso Internacional de Ergonomia e Usabilidade de Interfaces Humano Tecnológica: Produto, Informações Ambientes Construídos e Transporte

$16^{\circ}$ USIHC - Congresso Internacional de Ergonomia e Usabilidade de Interfaces Humano Computador

CINAHPA | 2017 - Congresso Internacional de Ambientes Hipermídia para Aprendizagem.

\section{REFERÊNCIAS BIBLIOGRÁFICAS}

FJORD trends 2017. Disponível em: <https://trends.fjordnet.com/wordpress/wpcontent/uploads/2017/01/Fjord_Trends_2017_MA STER_For_Download_V3.pdf >. Acesso em 22 de fevereiro de 2017.

Google Home. Disponível em:

<https://madeby.google.com/home/>. Acesso em15 de fevereiro de 2017.

Google Home Review. Disponível em: $<$ https://www.wareable.com/google/google-homereview>. Acesso em 17 de fevereiro de 2017.

Google Home Review, don't buy it. Disponível em: <http://www.businessinsider.com/googlehome-review-dont-buy-it-2016-12 >. Acesso em 17 de fevereiro de 2017.

Mukhopadhyay, Subhas Chandra. Internet of things: challenges and opportunities.

Palmerstorn North, New Zealand: Springer, 2014.

Murray, Janet. Inventing the medium: principles of interaction design as a cultural practice. Cambrigde, Massachusetts: MIT Press, 2012.

Norman, Donald A. O design do dia-a-dia. Rio de Janeiro: Rocco, 2006.

Preece, Jennifer. Design de interação: além da interação homem-computador. Jennifer Preece, Yvonne Rogers e Helen Sharp. Porto Alegre:

Bookman, 2013. 